\title{
PERFORMANCE OF THE REJUVENATED INJECTOR CONTROL SYSTEM IN SRRC
}

\author{
C. S. Chen, C. J. Wang, Jenny Chen, J. S. Chen, S. H. Lee, K. H. Hu, K. T. Hsu, K. K. Lin \\ Synchrotron Radiation Research Center \\ No 1, R\&D Road VI, Hsinchu Science-Based Industrial Park, Hsinchu, Taiwan, R.O.C.
}

\begin{abstract}
The original injector control system is a turnkey design and it was separated from the storage ring control system. It is not easy to maintain and install new devices. The control system of injector has been rejuvenated recently. There are two basic requirements for this plan, to provide more efficient and stable light source operation, and to reduce the maintenance resource need. Its implementation will also be helpful for improvement on reliability and control response time. Upgrade injector from $1.3 \mathrm{GeV}$ to $1.5 \mathrm{GeV}$ will be done before the end of 1999. The renewed injector control system will be able to provide improved environment for application program development and new devices installation. Automatic control operation for full energy injection will be implemented in SRRC.
\end{abstract}

\section{INTRODUCTION}

To simplify the system and provide upgrade options, injector control integration project has been launch in 1998 [1]. A homogeneous control system were put into operating from May 1999, it simplify the operation of the accelerator and get much more efficiency in operation, of course reduce the injection time. SRRC will be an automatic operation machine, topping-up mode test become possible in new control environment. A serial of application programs was built to support SRRC upgrade plans; full energy injector upgrades, new device installation and application program development. After the integration, it is not only to improve the performance but also to provide data logging and archiving service.

\section{NEW INJECTOR CONTROL SYSTEM ARCHITECTURE}

Figure 1 show the new injector control system, VME crates replace the original Intel PC that run the iRMX III operating system, the VME crates are the local controller in the main control system. In order to save the time, manpower and cost, it keep the two main subsystems, PLC system and BITBUS system. New booster control system has software architecture same as the SRRC storage ring control system, to modify and develop the application program is much easily. A simply user interface for the injector normal operation. New control system for SRRC booster is like a new life in the feature.

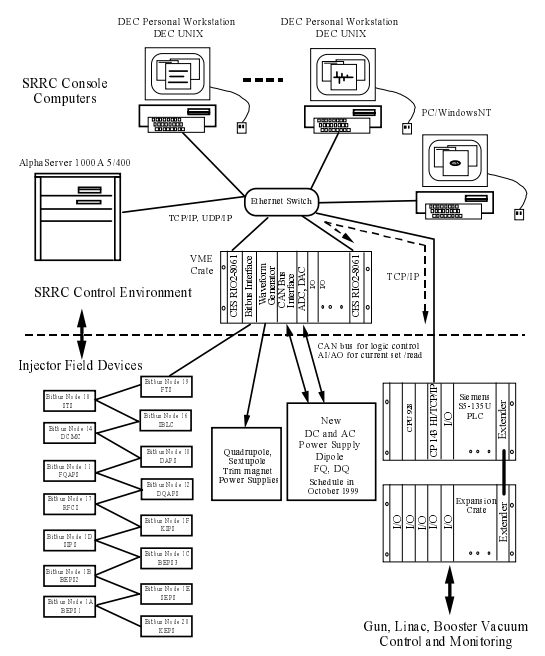

Figure 1. New injector control system configuration

\section{STRATEGICS OF CONTROL INTEGRATION}

Two local controller nodes were created for the integrated plan, one for PLC control interface, and another one for the master of the BITBUS network. These two nodes play a crucial role, as a protocol translator. Database format is fully same as the storage ring control system. An open and flexible control system just what we need, it has a grand advantage that is stable and easily maintains. An injector $1.5 \mathrm{GeV}$ upgrade will finish before the end of this year. New booster control system provides the base requirement to support these activities.

The storage ring has been upgrade to $1.5 \mathrm{GeV}$ operation in SRRC. Upgrade booster synchrotron from $1.3 \mathrm{GeV}$ to $1.5 \mathrm{GeV}$ to provide full-energy injection is under way. First, two cluster of power supply need to be replace, one is the dipole power supply of transport-line, and the other is the booster both DC and AC power supply. Second, in order to have enough safety margins and to avoid the insulation failure when operated at 1.5 $\mathrm{GeV}$ mode, a new septum magnet will be installed, and the extraction kicker must be increased $30 \%$ in field strength [2]. Third is the utilities, cooling water system and electricity capacity. 


\section{HIGH LEVEL APPLICATION}

It is not economically to modify the old injector control system and to build new application program to upgrade the function of injector control system. In the new environment, it provides data logging and archiving services. It is also easily to build a lattice file management for injector operation in the storage ring lattices file management. More application program will develop soon, some of these application is summary in following paragraphs.

In figure 2, a small size window shows the injector subsystem status. A serial of buttons was implemented for injector automatic operation. Beam current of the injector is displayed at the bottom in text and trend.

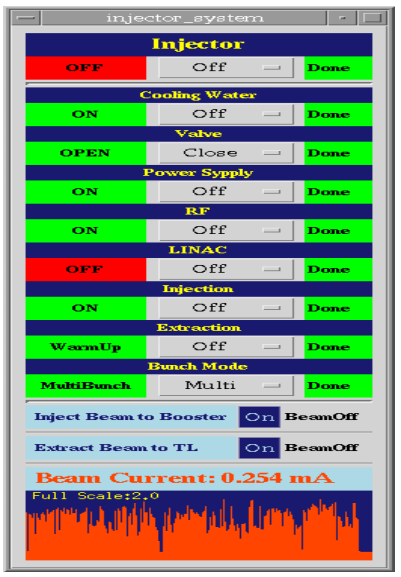

Figure 2. A user interface for the injector automatic operation

In figure 3., show graphical user interface of the linac system. A new environment for injector control and monitor is created by the control system integration in SRRC.

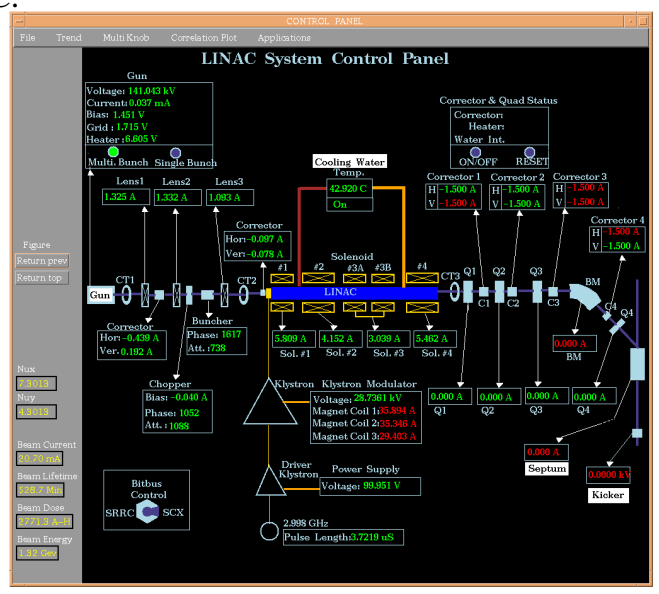

Figure 3. A graphical user interface for linac control

An application program was created for the new gun cathode high-voltage conditioning. In figure 4., it shows the procedure of anode high voltage processing.

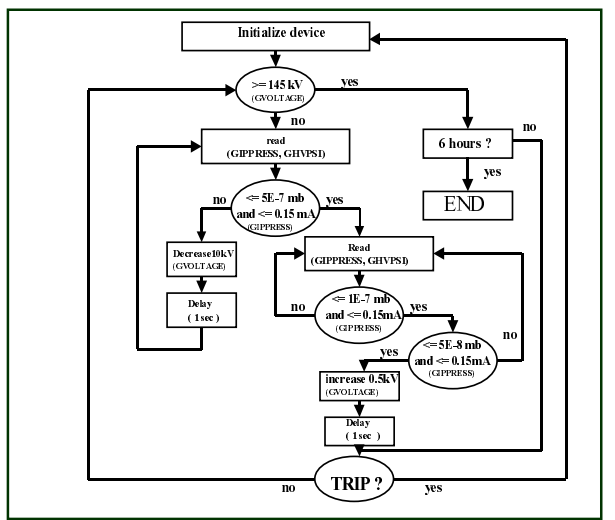

Figure 4. New gun cathode high-voltage conditioning

From the figure $5(\mathrm{a}, \mathrm{b}, \mathrm{c})$, they show the conditioning process history. Because the application programs support, this time save a lot of time and manpower in this procedure.

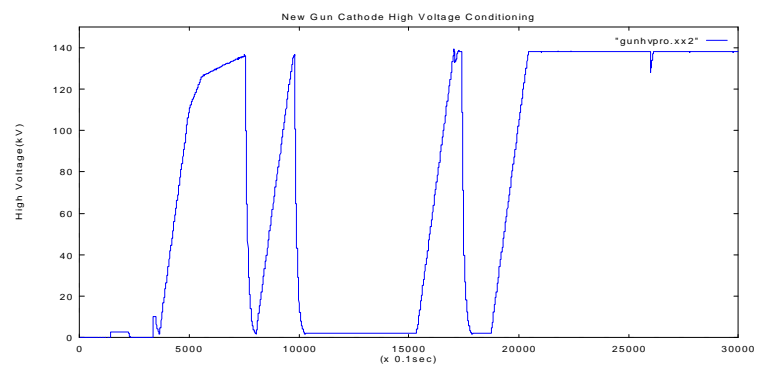

(a) Anode High Voltage

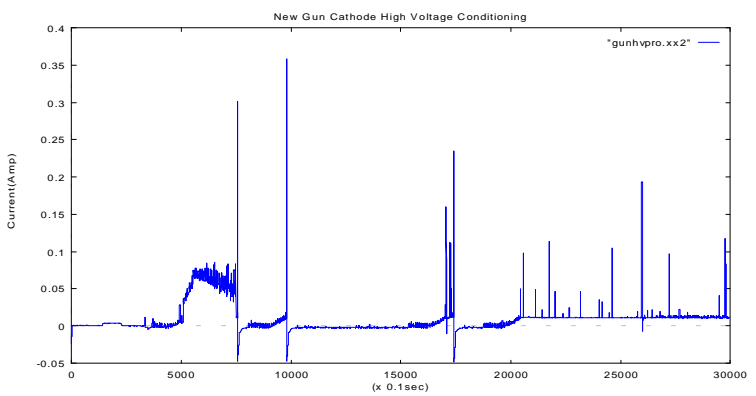

(b) Cathode Emission Current

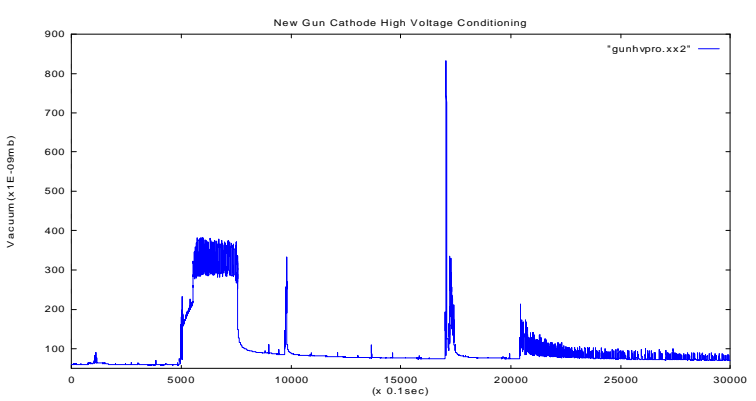

(c) Vacuum Pressure

Figure 5. A history for new gun cathode high-voltage conditioning 


\section{NEW FEATURE OF RENEWED CONTROL SYSTEM}

In the new injector control system, it also has three layers structure. The second layer is VME crate; running real time operation system, it is local controller in new control environment, improved performance are in speed and reliability than the old booster control system. Its input and output channel update rate is about 4 times per second, this result that is acceptable for the new injector control system. Reproducibility is an important requirement for machine automatic operation. The first layer consists of a process computer and several console workstations, these keep all information relating to the controlled parameters and provides the graphic user interface for the machine operation. In the third layer, the new injector control system keeps the BITBUS network system and PLC system.

In order to accommodate $1.5 \mathrm{GeV}$ upgrade, several of BITBUS nodes will be obsolete for new placed devices. Newly installed devices will connect to VME crate directly. New power supply control interfaces will build in the VME crate. As shown in figure 6., the design is similar with reference [3]. It provides amplitude reference to DC power supply and provides phase and amplitude regulated high spectral purity $10 \mathrm{~Hz}$ reference to $\mathrm{AC}$ power supplies in the new injector control system.

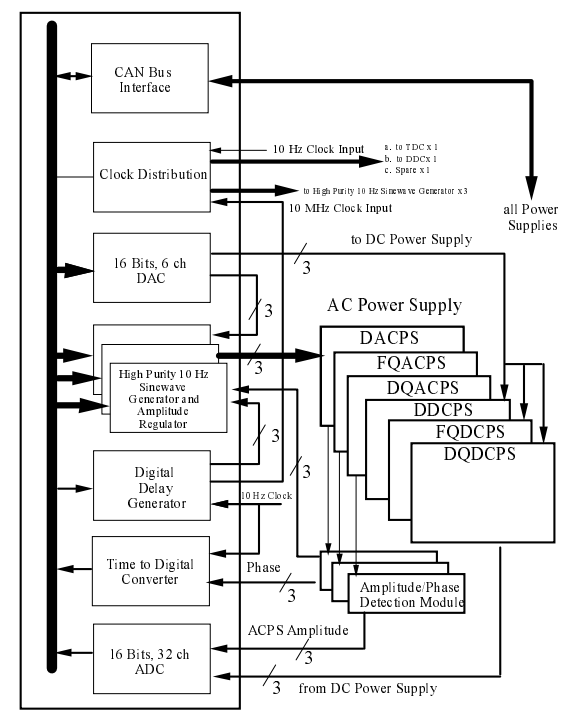

Figure 6. New power supply control interface

In the booster magnet system, each magnet group is powered from a White circuit. It operates on $10 \mathrm{~Hz}$ and provides a sine-wave current swinging. Both phase and amplitude of the AC power supply should be controlled. The task of the phase and amplitude regulation loop is to monitor and control the both phase and amplitude of current between the dipole, the defocusing quadrupole, and the focusing quadrupole. In order to improve the phase regulation, a proper controller is need. A PID controller is used in the phase regulation loop now.

New Control system provide data archiving service. From the figure 7, Linac cooling water temperature regulating loop history. It is impossible to monitor the signal in the old control system environment.

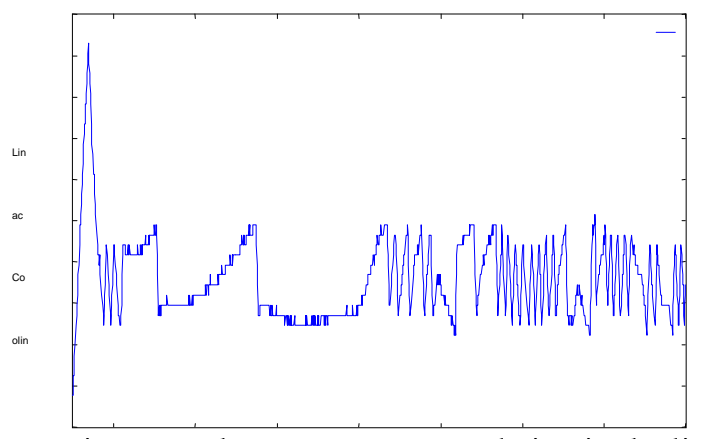

Figure 7. The temperature regulation in the linac cooling water unit.

To improve performance of injector, several projects are on going; such as linac RF feedforward, close orbit measurement [4], these will be put into operation soon.

\section{CONCLUSIONS}

A homogeneous control system is introduced by the new integrated injector control system plan. In order to reduce the budget, manpower and time need, the integration work keeps most of the field level devices. The new control system provides a basis for injector 1.5 $\mathrm{GeV}$ upgrade plans. It supports new devices installation and upgrade plans, and it also supports the application program development.

\section{ACKNOWLEDGMENTS}

The authors express thanks to the staffs of the light source division and the instrument and development division for their cooperation in $1.5 \mathrm{GeV}$ upgrade project, and the helps from the staffs of administration are also appreciated.

\section{REFERENCES}

[1] C. S. Chen, et al., "Control Integration for the Injector in SRRC" Proceedings of the 6th European Particle Accelerator Conference, Stockholm, 22-26 June 1998, p.1658.

[2] J. P. Chiou, et al., "The Upgrade of SRRC Booster Extraction System", these proceeding.

[3] K. Buerkmann, et al., "Performance of the White circuits of the BESSY II booster synchrotron", Proceedings of the 6th European Particle Accelerator Conference, Stockholm, 22-26 June 1998, p.2062.

[4] K. H. Hu, et al., "Closed Orbit Measurement System for the Booster Synchrotron in SRRC”, these proceeding. 